\title{
High-Temperature Friction and Wear Properties of NiCr/hBN Self-Lubricating Composites
}

\author{
Xuewei Zhu®, Xiaofeng Wei *, Yuxiang Huang, Fu Wang and Pengpeng Yan \\ College of Mechanical and Electronic Engineering, Northwest A\&F University, Yangling 712100, China; \\ zxw_83614@163.com (X.Z.); hyx@nwsuaf.edu.cn (Y.H.); wangfu@nwafu.edu.cn (F.W.); \\ yanpengpeng@nwafu.edu.cn (P.Y.) \\ * Correspondence: wxf8412@nwafu.edu.cn; Tel.: +86-151-0295-8462
}

Received: 30 January 2019; Accepted: 14 March 2019; Published: 20 March 2019

\begin{abstract}
NiCr/hBN self-lubricating composites with hBN solid-lubricant contents of $8 \%, 9 \%, 10 \%$, $11 \%$, and $12 \%$ (mass fractions) were prepared by powder-metallurgy method. Their tribological properties at room temperature and 600,700 , and $800{ }^{\circ} \mathrm{C}$ were studied. SEM and XRD were performed to analyze their wear-surface morphology and abrasive-dust composition. Results indicate that the $\mathrm{NiCr} / \mathrm{hBN}$ self-lubricating composites have favorable tribological properties at room temperature and $600{ }^{\circ} \mathrm{C}$. The optimum comprehensive friction and wear performance are achieved at $10 \% \mathrm{hBN}$, and the main wear mechanism is abrasive wear. At 700 and $800{ }^{\circ} \mathrm{C}$, the friction and wear properties of $\mathrm{NiCr} / \mathrm{hBN}$ self-lubricating composites obviously decline. The wear surface experiences oxidation and the spinel oxides $\mathrm{Cr} 2 \mathrm{O} 3, \mathrm{NiCr} 2 \mathrm{O} 4$, and $\mathrm{CrBO} 3$ are formed. The main wear mechanism becomes combined scratching and glue form of adhesive wear, leading to greatly increased wear rate for the $\mathrm{NiCr} / \mathrm{hBN}$ sel-lubricating composites.
\end{abstract}

Keywords: self-lubricating composites; $\mathrm{NiCr} / \mathrm{hBN}$; elevated temperature tribological behavior; wear mechanism

\section{Introduction}

In aero-engines, the high-temperature alloy $\mathrm{NiCr}$ is used as the base material of the sealing material between the blade and cartridge receiver because of the alloy's high-temperature wear resistance, oxidation resistance, and high-temperature mechanical behaviors [1-3]. For aero-engine operation, the sealing material should be usable for a long time at high temperatures and should exert a certain self-lubrication antifriction effect. Thus, self-lubricating composite preparation by adding solid lubricant to the NiCr-based alloy has become an important research subject and is thus extensively studied $[4,5]$.

Solid lubricants commonly used in self-lubricating composites generally include graphite, MoS2, $\mathrm{CaF} 2, \mathrm{BF} 2$, and hexagonal boron nitride (hBN), where graphite and MoS2 can be used only at $\angle 500^{\circ} \mathrm{C}$ as restricted by their own physical properties [6,7]. $\mathrm{CaF} 2$ and $\mathrm{BaF} 2$ have favorable lubricating properties at high temperatures, but they are generally used under dry-friction conditions [8]. Conversely, hBN has favorable lubricating properties under dry and wet conditions [9]. It has a planar hexagonal net layer crystal structure similar to the hexagonal crystal system structure of graphite. This feature corresponds to a large atomic spacing along the direction of the axis $\mathrm{c}$, a small binding force, and easy interlayer sliding, which lead to the excellent lubricating property of hBN. Thus, hBN is a preferable solid lubricant in metal-matrix composites for high-temperature applications in the aviation industry $[10,11]$.

The lubrication and mechanical properties of $\mathrm{NiCr} / \mathrm{hBN}$ composites are negatively correlated, so preparing $\mathrm{NiCr} / \mathrm{hBN}$ composites with good comprehensive properties is challenging. Thus, the sintering process and composition optimization of $\mathrm{NiCr} / \mathrm{hBN}$ composites, as well as their 
influence on the composites' room-temperature friction and wear mechanism, have been extensively studied [12-15]. With increased hBN content from 5\% to 10\%, the physical and mechanical properties of hBN composites gradually decline, although their tribological properties can be improved. When the hBN content exceeds $10 \%$, the wear rate of the self-lubricating composite increases due to the low strength of the matrix material [12]. Bingyu [13,14] indicated that $\mathrm{NiCr} / \mathrm{hBN}$ composites achieve the optimum properties at $8-12 \% \mathrm{hBN}$ content. Currently, studies on the tribological properties of $\mathrm{NiCr} / \mathrm{hBN}$ self-lubricating composites are restricted to the normal-temperature stage. According to the working features of an engine, the working temperature of $\mathrm{NiCr} / \mathrm{hBN}$ material generally exceeds $400{ }^{\circ} \mathrm{C}$. Changchuan [15] studied the oxidation behaviors of the $\mathrm{NiCr} / \mathrm{hBN}$ composites at $>600{ }^{\circ} \mathrm{C}$. They found that the material has favorable high-temperature stability at $600{ }^{\circ} \mathrm{C}$ and undergoes oxidation at $>700{ }^{\circ} \mathrm{C}$. However, no study has reported on the friction and wear properties of $\mathrm{NiCr} / \mathrm{hBN}$ composites at high temperatures.

In the present work, Ni-20Cr alloy was used as the matrix, and then $8 \%, 9 \%, 10 \%, 11 \%$, and $12 \%$ $\mathrm{hBN}$ solid lubricants were added to study the friction and wear behaviors of $\mathrm{NiCr} / \mathrm{hBN}$ self-lubricating composites at room temperature $\left(25^{\circ} \mathrm{C}\right)$ and 600,700 , and $800^{\circ} \mathrm{C}$. Our results can provide a theoretical basis for the application of $\mathrm{NiCr} / \mathrm{hBN}$ composites in the aero-engine industry.

\section{Experiment}

\subsection{Preparation of $\mathrm{NiCr} / \mathrm{hBN}$ Composites}

Metals taken as Ni-20Cr alloy ingot were prepared by vacuum melting with high-purity raw metal materials ( $\mathrm{Cr}$ and $\mathrm{Ni}$ ), and $\mathrm{Ni}$-20Cr powders were prepared by atomization technology in argon atmosphere. The powders used to prepare samples were sieved until their average particle size was $<48 \mu \mathrm{m}$. Hexagonal crystal hBN powders (produced by Dandong Rijin Technology Co., Ltd., Dandong, China; average particle size $<5 \mu \mathrm{m}$ ) were selected to metalize Ni by chemical precipitation [12]. The metalized hBN solid lubricant was blended with Ni-20Cr alloy powders by pressing into long blocks with dimensions of $38 \mathrm{~mm} \times 6 \mathrm{~mm} \times 6 \mathrm{~mm}$ and wafers with dimensions of $\Phi 43 \mathrm{~mm} \times 3 \mathrm{~mm}$ under $300 \mathrm{MPa}$ pressure at room temperature. The hBN contents in the samples were $8 \%, 9 \%, 10 \%$, $11 \%$, and $12 \%$, and the pressed pressure was maintained for $8 \mathrm{~s}$. After sample preforming, they were sintered for $120 \mathrm{~min}$ at $1150{ }^{\circ} \mathrm{C}$ and vacuum degree of $1 \times 10^{-3} \mathrm{~Pa}$ to $3 \times 10^{-3} \mathrm{~Pa}$. To improve the compactness and mechanical properties of the composites, the pre-sintered specimens were re-pressed under $600 \mathrm{MPa}$ pressure and then annealed at $850{ }^{\circ} \mathrm{C}$ in a vacuum furnace for $60 \mathrm{~min}$ to obtain the $\mathrm{NiCr} / \mathrm{hBN}$ composites.

\subsection{Friction and Wear Property Tests}

Friction and wear property tests of the composites were implemented on an MMU-10G high-temperature friction and wear tester (Ji'nan Lanbo Test Equipment Co. Ltd., Ji'nan, China). The friction pair used in the test was a $1 \mathrm{Cr} 18 \mathrm{Ni}$ Ti annular pad with $40 \mathrm{~N}$ load and $250 \mathrm{r} / \mathrm{min}$ revolving speed. The experimental ambient temperature was room temperature (about $25^{\circ} \mathrm{C}$ ) and ambient humidity was about $40 \%$. The test specimens were prepared in a $\Phi 43 \mathrm{~mm} \times 3 \mathrm{~mm}$ wafer in advance, polished into 1200\# abrasive paper, and rinsed using ethyl alcohol. During the test process, the machine automatically read the friction coefficient and then calculated the wear extent through the weighing method. An analytical balance was used to weigh the specimens before and after the friction at $0.001 \mathrm{~g}$ precision. The average wear rate $K$ was calculated as follows:

$$
K=\frac{m_{1}-m_{2}}{\rho t}
$$

where $m_{1}$ and $m_{2}$ are the specimen masses before and after friction $(\mathrm{g})$, respectively, $\rho$ is the real density of the specimen, and $t$ is the friction time $(\mathrm{min})$. The reported results were averaged from at least five measurements. 


\subsection{Analytical Test}

The density of the $\mathrm{NiCr} / \mathrm{hBN}$ self-lubricating composite was detected through the wax immersion-drainage method, and the porosity $\eta_{V}$ of the composite was calculated through Equation (2).

$$
\eta_{V}=\left(1-\frac{D_{\mathrm{V}}}{D_{0}}\right) \times 100 \%
$$

where $D_{0}$ is the theoretical density of the specimen and $D_{\mathrm{V}}$ is the measured density of the specimen (unit $\mathrm{g} / \mathrm{cm}^{3}$ ).

The three-point flexural-strength detection of the specimen was carried out on a CCS- 44100 universal electronic testing machine (Ji'nan Ruima Machinery Equipment Co., Ltd., Ji'nan, China). A RigakuD-MAX 2000 X-ray diffractometer (Rigaku Corporation, Tokyo, Janpan) was used for the phase analysis of abrasive dusts, and the detection angle was within $10^{\circ}-80^{\circ}$. The fracture appearance and wear-surface morphology of the specimens were observed with a Sirion200 field-emission scanning electron microscope (FEI Corporation, Hillsboro, OR, USA).

\section{Results and Discussion}

\subsection{Physical and Mechanical Properties of NiCr/hBN Composites}

The effects of hBN contents on the density, porosity, and flexural strength of the $\mathrm{NiCr} / \mathrm{hBN}$ self-lubricating composites are shown in Figure 1 . The density of the $\mathrm{NiCr} / \mathrm{hBN}$ composites showed an approximately linear decline with increased $\mathrm{hBN}$ content. The material porosity gradually increased with increased $\mathrm{hBN}$ content, and an inflection point appeared at $10 \% \mathrm{hBN}$. Thus, at this point, the rising amplitude of material porosity increased. Material flexural strength also gradually declined with increased hBN content, and an inflection point appeared at $10 \% \mathrm{hBN}$ as well. This finding means that increased $\mathrm{hBN}$ content from $8 \%$ to $10 \%$ led to slowly decreased flexural strength of $\mathrm{NiCr} / \mathrm{hBN}$ composites; conversely, increased content from $10 \%$ to $12 \%$ led to abruptly decreased flexural strength of the material.

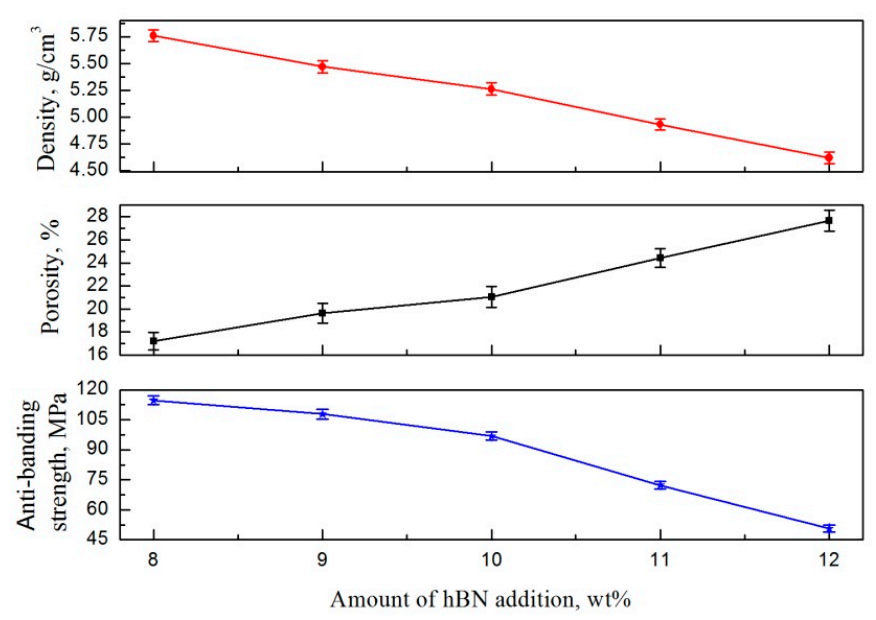

Figure 1. Influence of hBN content on the density, porosity, and flexural strength of $\mathrm{NiCr} / \mathrm{hBN}$ composites.

Figure 2 shows three-point flexural fracture appearance of $\mathrm{NiCr} / \mathrm{hBN}$ composites with $\mathrm{hBN}$ contents of $8 \%, 9 \%, 10 \%$, and $12 \%$. Spherical $\mathrm{NiCr}$ alloy particles and pinnate hBN powders are observed. When the hBN content was $8 \%$, an obvious sintering well formed between $\mathrm{NiCr}$ particles due to the diffusion and bonding during sintering, as shown in Figure 2a. However, when the hBN content was increased to $9 \%$ and $10 \%$, the $\mathrm{hBN}$ powders dispersed among $\mathrm{NiCr}$ particles hindered the diffusion and bonding, as shown in Figure $2 b$,c. Considering the large difference between the densities of $\mathrm{hBN}\left(2.28 \mathrm{~g} / \mathrm{cm}^{3}\right)$ and $\mathrm{NiCr}$ alloy $\left(8.47 \mathrm{~g} / \mathrm{cm}^{3}\right)$, the volume fraction of $\mathrm{hBN}$ increased by about 
$2.5 \%$ when its mass fraction increased by $1 \%$, which resulted in increased quantity of hBN powders dispersed among NiCr particles. During preparation, hBN was dispersed between NiCr particles with favorable thermal stability and low sintering activity. It hindered the mutual diffusion among $\mathrm{NiCr}$ particles, and a greater hBN content corresponded to more obvious hindering effect, so the flexural strength of the composite gradually declined with increased hBN content. When the hBN content was $12 \%$, its volume fraction exceeded $30 \%$, so the sintering of $\mathrm{NiCr}$ particles was seriously hindered and no obvious sintering well formed on the material fracture, as shown in Figure $2 \mathrm{~d}$. Thus, the flexural strength of the material dropped sharply.
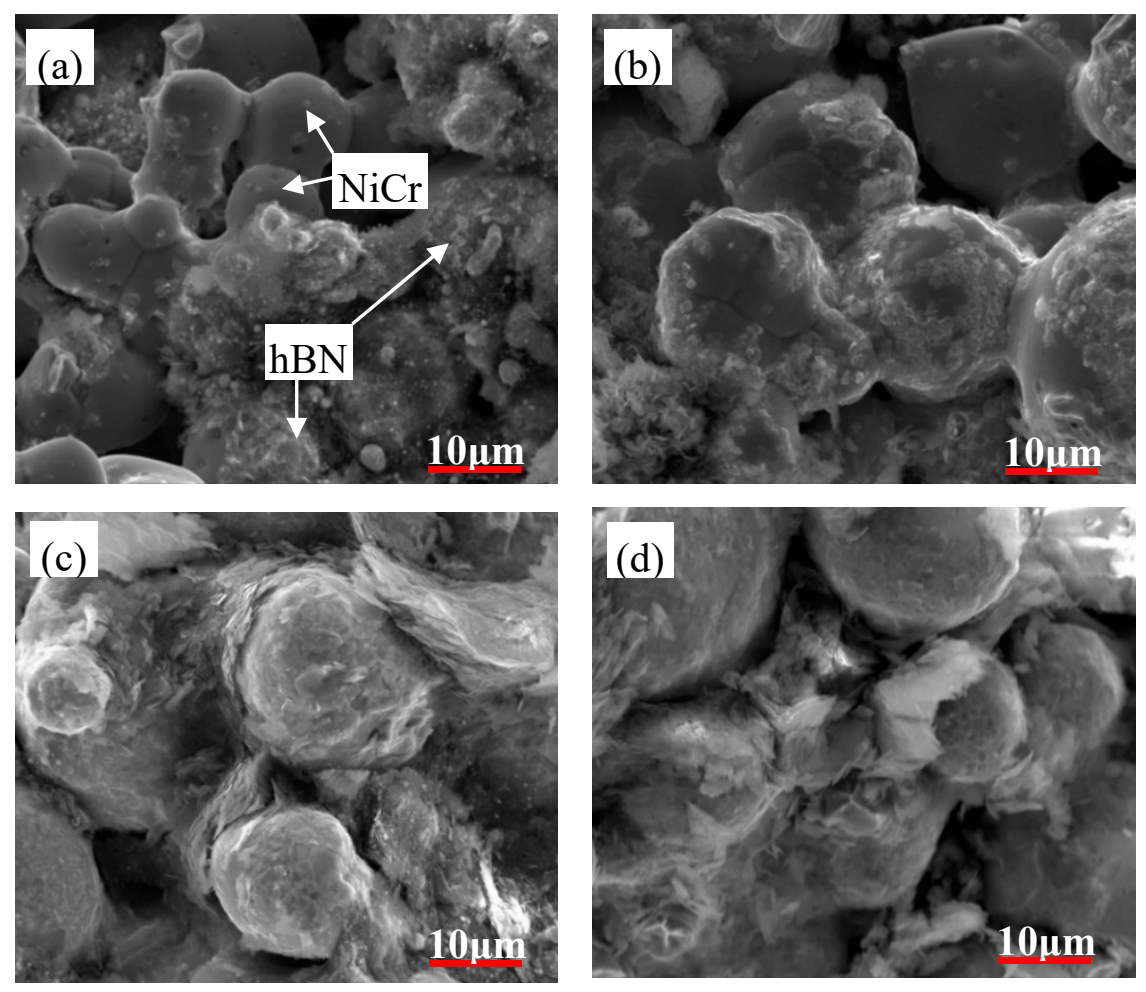

Figure 2. Fracture appearances of $\mathrm{NiCr} / \mathrm{hBN}$ composites with different hBN contents: (a) $8 \%$, (b) $9 \%$, (c) $10 \%$; and (d) $12 \%$.

Pores are known to become the areas of stress concentration under external loads, leading to the generation of microcracks and the decline of a material's mechanical properties. With increased porosity, the influence of porosity on material properties is strengthened, and the material strength declines more obviously. According to the fracture appearance in Figure 2, pores obviously increased as hBN content increased; the sintering necks of $\mathrm{NiCr}$ particles and the bonding force among particles were reduced. Increased porosity can further decrease the compactness degree of the material and reduces strength of the sintering body.

The relationship between porosity $\theta$ and flexural strength $\sigma_{b}$ is [16]

$$
\sigma_{b}=\sigma_{0} e^{-\beta \theta}
$$

where $\sigma_{0}$ is the flexural strength of the material with porosity approaching zero and is approximately equal to the flexural strength of the compact material; and $\beta$ is a constant related to the pore shape. According to Equation (3), the flexural strength of the composite significantly declines with increased porosity $\theta$, which is identical with the experimental result as shown in Figure 1. 


\subsection{High-Temperature Friction and Wear Properties of NiCr/hBN Composites}

The change in friction coefficient of the $\mathrm{NiCr} / \mathrm{hBN}$ composites containing $10 \% \mathrm{hBN}$ with friction time at different temperatures is shown in Figure 3 . At 25 and $600{ }^{\circ} \mathrm{C}$, the material friction coefficient was high in the initial friction phase and declined to a steady level after about $20 \mathrm{~min}$. The stable friction coefficient at room temperature $w$ lower than that at $600{ }^{\circ} \mathrm{C}$. At 700 and $800{ }^{\circ} \mathrm{C}$, the material friction coefficient was low in the initial friction phase, taking about $10 \mathrm{~min}$ to reach the stable friction phase in the test; after the stable phase, the friction coefficient of the composite increased and became less stable than that at 25 and $600{ }^{\circ} \mathrm{C}$. The stable friction coefficients of $\mathrm{NiCr} / 10 \% \mathrm{hBN}$ composites were about $0.28,0.35,0.56$, and 0.63 at $25,600,700$, and $800^{\circ} \mathrm{C}$, respectively.

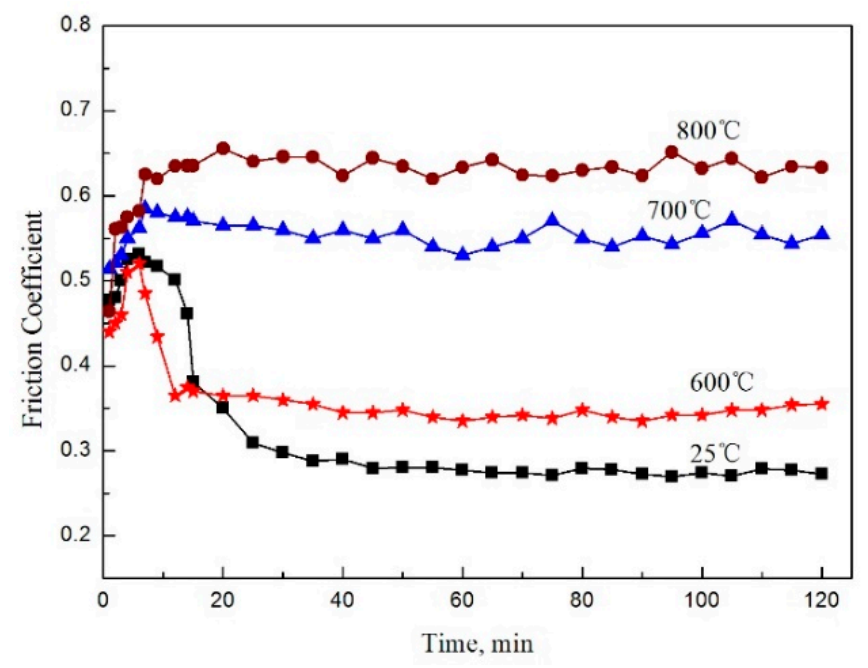

Figure 3. Friction coefficient vs. time curves of friction pairs.

The schematic of the formation of $\mathrm{NiCr} / \mathrm{hBN}$ self-lubricating composite films during sliding friction is shown in Figure 4. The $\mathrm{NiCr} / \mathrm{hBN}$ composite is regarded as a whole, whereas the solid lubricant hBN is uniformly distributed throughout the material. Before the friction phase starts, the contact surface of friction pairs was the contact surface between the metal matrix and mating material, as shown in Figure 4a. At the same time, it was in a nonsolid lubrication state, so friction coefficients in the initial friction phase at all temperatures were large (Figure 3). When the initial friction phase was started, the surface of the composite experienced deformation due to extrusion, and a large quantity of friction heat was generated. The hBN solid lubricant that was uniformly distributed throughout the material gradually flowed toward the friction surface after extrusion, and the friction surface transformed into a mixed surface of solid lubricant and metal matrix, as shown in Figure $4 \mathrm{~b}$. Thus, the friction coefficient between friction pairs gradually declined. As the extrusion-induced deformation continued, the hBN content on the friction surface continuously increased. Given the small shear strength of $\mathrm{hBN}$, it was sheared and spread out on the external surface under the effect of frictional force, and a lubricating film with complete coverage formed, as shown in Figure 4c. This time, the friction coefficient between friction pairs reached a stable state.

According to the formation mechanism of the solid lubricating film, Blau et al. [17] proposed that when the solid lubricating film consists of metal matrix and solid lubricating film, the friction coefficient between friction pairs can be expressed as follows:

$$
\mu=\frac{F}{N}=n \mu_{e}+(1-n) \mu_{m}
$$

where $\mu m$ is the friction coefficient between the metal matrix and mating material, and $\mu_{e}$ is the friction coefficient between the solid lubricating film and mating material. When $n=1$, the friction surface reaches a complete solid-lubrication state and $\mu=\mu_{e}$; thus, the friction coefficient is equal 
to that of pure hBN (about 0.25) [10]. When $n=0$, the friction surface is in a nonsolid lubrication state and $\mu=\mu_{m}$; thus, the friction coefficient is equal to the friction coefficient of pure $\mathrm{NiCr}$ matrix (about 0.46) [18]. Accordingly, if the Ni-Cr/hBN composite does not undergo oxidation, then the lubricating film consists of solid lubricant and metal matrix and its friction coefficient is between 0.25 and 0.46 (Figure 3) at room temperature and $600{ }^{\circ} \mathrm{C}$. However, with increased friction temperature to 700 and $800^{\circ} \mathrm{C}$, the friction coefficient is much higher than that of $\mathrm{NiCr}$ matrix, indicating the presence of components with a high friction coefficient in the lubricating film.

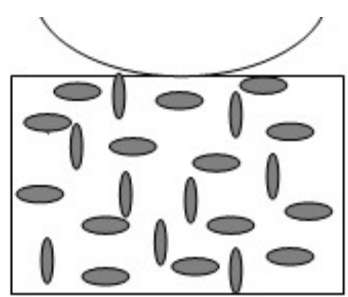

(a)

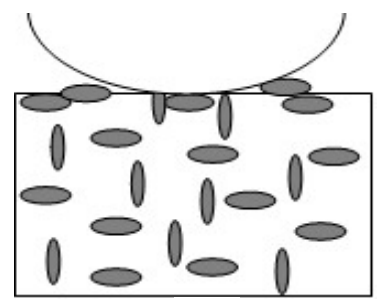

(b)

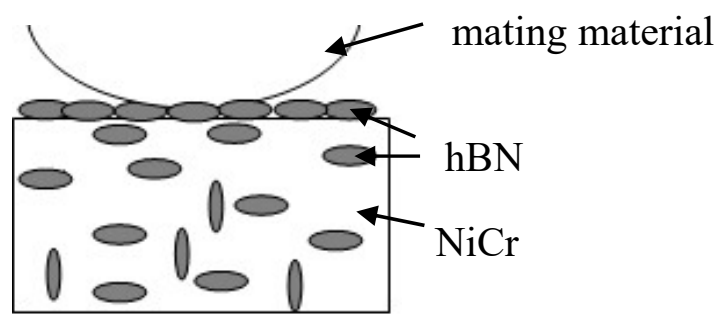

(c)

Figure 4. Schematic of the formation of solid lubricating film for $\mathrm{NiCr} / \mathrm{hBN}$ composite: (a) pre-friction stage, (b) initial friction stage; and (c) stable friction stage.

To investigate the friction and wear behavior of $\mathrm{NiCr} / \mathrm{hBN}$ composite at high temperature, the friction coefficients and wear rates of the materials with different $\mathrm{hBN}$ contents at various friction temperatures were tested in this study. Figure 5 shows the change curves of the friction coefficient of $\mathrm{NiCr} / \mathrm{hBN}$ composites with different $\mathrm{hBN}$ contents at different friction temperatures. When the friction temperature was room temperature and $600{ }^{\circ} \mathrm{C}$, the friction coefficient initially decreased and then increased with increased $\mathrm{hBN}$ content and reached the minimum value at $10 \% \mathrm{hBN}$ content. When the friction temperature was 700 and $800{ }^{\circ} \mathrm{C}$, the friction coefficient increased with increased hBN content. When the hBN content was constant, the friction coefficients of the $\mathrm{NiCr} / \mathrm{hBN}$ composites increased with increased friction temperature.

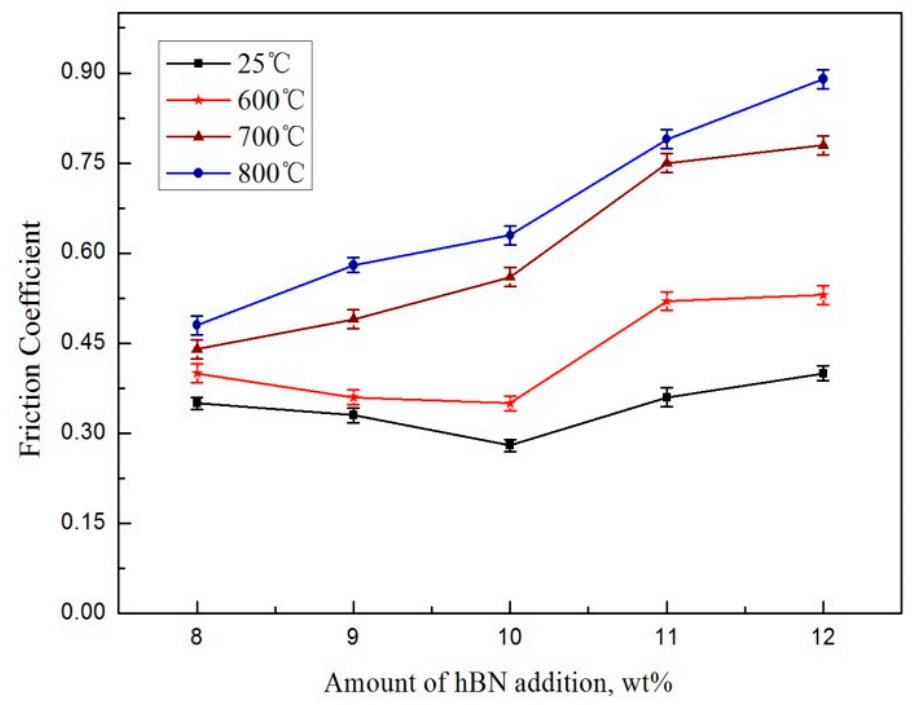

Figure 5. Influence of $\mathrm{hBN}$ content on the friction coefficient of $\mathrm{NiCr} / \mathrm{hBN}$ composite at different friction temperatures.

Figure 6 shows the change curves of $\mathrm{NiCr} / \mathrm{hBN}$ composite with different $\mathrm{hBN}$ contents at different friction temperatures. At room temperature, the wear rate of $\mathrm{NiCr} / \mathrm{hBN}$ composite initially decreased and then increased with increased hBN content, reaching the minimum value when the hBN content was $10 \%$. At $600{ }^{\circ} \mathrm{C}$, the wear rate of the $\mathrm{NiCr} / \mathrm{hBN}$ composite initially increased gradually and then 
increased abruptly when the hBN content exceeded $10 \%$, which indicates that the wear mechanism of the material changes when the hBN content exceeds $10 \%$. At $700{ }^{\circ} \mathrm{C}$, the wear rate of the $\mathrm{NiCr} / \mathrm{hBN}$ composite linearly increased, but at $800{ }^{\circ} \mathrm{C}$, the wear rate of the material abruptly increased with increased hBN content from $8 \%$ to $9 \%$. When hBN content exceeded $9 \%$, the wear rate increased slowly and remained unchanged.

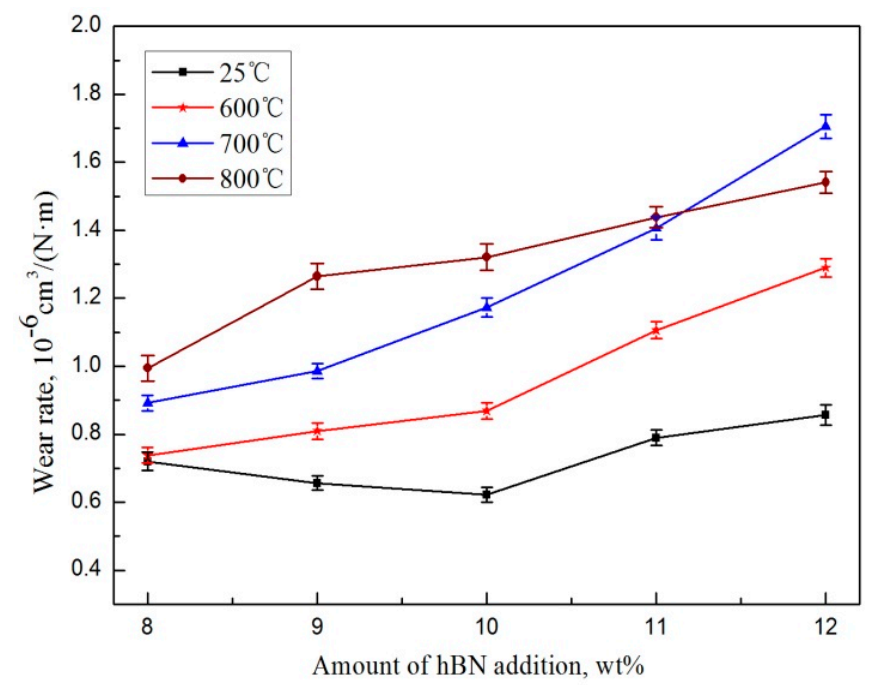

Figure 6. Influence of hBN content on the wear rate of $\mathrm{NiCr} / \mathrm{hBN}$ composite at different friction temperatures.

The wear-surface morphologies of $\mathrm{NiCr} / \mathrm{hBN}$ self-lubricating composite under different frictional conditions are shown in Figure 7. At room temperature, the lubricating-film coverage on the wear surface of $\mathrm{NiCr} / \mathrm{hBN}$ composite containing $8 \% \mathrm{hBN}$ was incomplete, and the boundary of $\mathrm{NiCr}$ particles was vague, as shown in Figure 7a; the friction coefficient was the maximum. When the hBN content was $10 \%$, the lubricating-film coverage was complete and the friction coefficient reached the minimum value. With increased temperature to $600{ }^{\circ} \mathrm{C}$, the lubricating film basically covered the entire wear surface of $\mathrm{NiCr} / \mathrm{hBN}$ composite containing $10 \% \mathrm{hBN}$, as shown in Figure $7 \mathrm{c}$, so the friction coefficient remained low. However, the wear surface loosened with peeling pits forming in local parts, and then the wear rate slightly increased. When the hBN content was increased to $12 \%$, the lubricating film fell off and its coverage on the specimen surface was incomplete, as shown in Figure $7 \mathrm{~d}$, so both friction coefficient and wear rate obviously increased. At $800{ }^{\circ} \mathrm{C}$, obvious furrows appeared on the wear surface of $\mathrm{NiCr} / \mathrm{hBN}$ material containing $10 \% \mathrm{hBN}$ with peeling pits forming in local parts, as shown in Figure 7e. A large area on the wear surface of $12 \% \mathrm{hBN}$ material fell off and almost no lubricating film existed, as shown in Figure $7 \mathrm{f}$, so its wear rate was large at $800{ }^{\circ} \mathrm{C}$. 

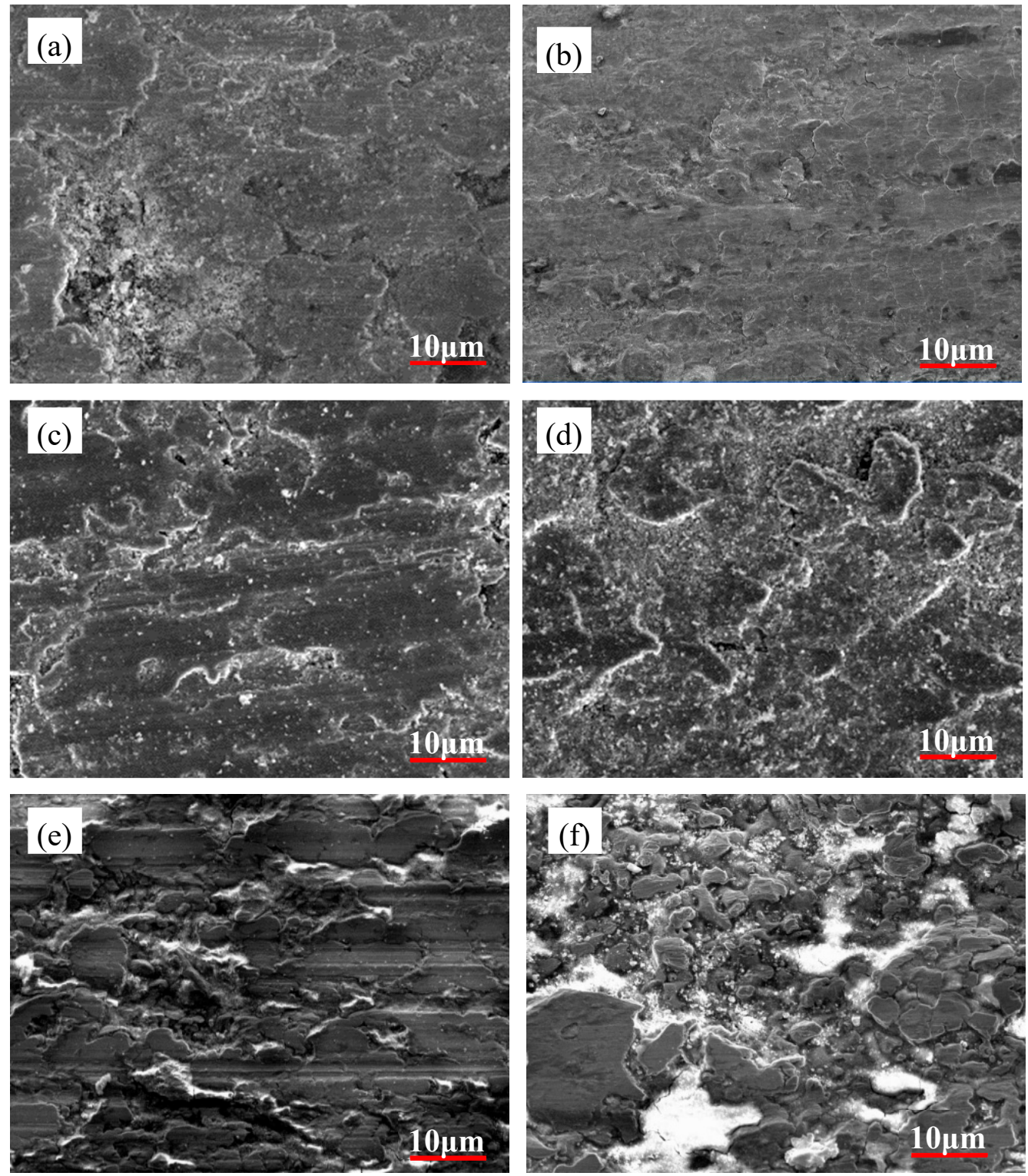

Figure 7. Wear-surface morphologies of the $\mathrm{NiCr} / \mathrm{hBN}$ self-lubricating composites under different friction conditions: (a) $8 \% \mathrm{hBN}, 25^{\circ} \mathrm{C}$; (b) $10 \% \mathrm{hBN}, 25^{\circ} \mathrm{C}$; (c) $10 \% \mathrm{hBN}, 600{ }^{\circ} \mathrm{C}$; (d) $12 \% \mathrm{hBN}, 600{ }^{\circ} \mathrm{C}$; (e) $10 \% \mathrm{hBN}, 800{ }^{\circ} \mathrm{C}$; and (f) $12 \% \mathrm{hBN}, 800{ }^{\circ} \mathrm{C}$.

\subsection{Analysis of the High-Temperature Friction and Wear Mechanism of NiCr/hBN Composites}

According to the formation mechanism of the lubricating film, it forms on the friction surface of $\mathrm{NiCr} / \mathrm{hBN}$ composite accompanied by processes such as material deformation and hBN flow, so the formation of the lubricating film is related to factors such as the strength of the composite material, magnitude of load, and hBN content. In other words, decreased material strength, increased magnitude of load, or increased hBN content can all promote the formation of the lubricating film and reduce the friction coefficient, thereby improving the lubrication properties. However, according to Figure 5, the friction coefficient of $\mathrm{NiCr} / \mathrm{hBN}$ composite does not gradually decrease with increased hBN content and decreased material strength because the favorable tribological properties of the material depends on the formation capacity of the lubricating film and on the wear rate of the lubricating film.

The wear rate of the lubricating film is influenced by the strength of the composite and the repair ability and wear resistance of the solid lubricating film. First, if the strength of the composite is too low, 
then the shear force during the friction process goes deeply into the material such that the matrix is torn and peeled off. Thus, the lubricating film difficultly retains its integrity because it loses the support from the matrix; consequently, the lubrication properties of the composite decline. Second, after the solid lubricating film is peeled off, the solid lubricant in the matrix continues to be extruded outside. At this time, the solid lubricant must guarantee sufficient content and favorable mobility to form a new lubricating film and fill the void caused by wear and, thus, guarantee good lubrication properties. Furthermore, the matching between solid lubricant and matrix, the matrix-surface conditions, and the composition and thickness of the solid lubricating film directly affect the wear resistance of the lubricating film.

At room temperature and $600{ }^{\circ} \mathrm{C}$, the strength of the $\mathrm{NiCr} / \mathrm{hBN}$ composite increases with increased hBN content from $8 \%$ to $10 \%$. The main wear mechanism of the composite is abrasive wear, and its abrasive dusts mainly present a flocculent shape with fine and uniform particle sizes, or a small quantity of massive abrasive dusts appear as shown in Figure 8a,b. To identify the physical phases of abrasive dusts, XRD analysis was carried out, and results are shown in Figure 9 . As the physical phase at $25^{\circ} \mathrm{C}$ is basically identical with that at $600{ }^{\circ} \mathrm{C}$, the analytic curve of abrasive dusts at room temperature is neglected in the figure. As shown in Figure 9, abrasive dusts are mainly hBN and $\mathrm{Ni}(\mathrm{Cr})$ alloy at $600{ }^{\circ} \mathrm{C}$. Combined with the wear-surface morphologies shown in Figure 7a-C, plastic deformation on the material surface is found to be slight at room temperature and $600{ }^{\circ} \mathrm{C}$. Bulges on the material surface fall off and are separated under the effect of shear force, and abrasive particles are formed. This wear form usually occurs at the surface layer of the solid lubricating film and can be repaired through the material self-consumption effect with flat wear surface, so the wear process is relatively stable. When the hBN content reaches $12 \%$, the sintering degree of the composite is lowered, and the strength abruptly declines. As the supporting effect of the matrix declines, the wear resistance of the lubricating film decreases, and adhesive wear occurs locally, as shown in Figure $7 \mathrm{~d}$.
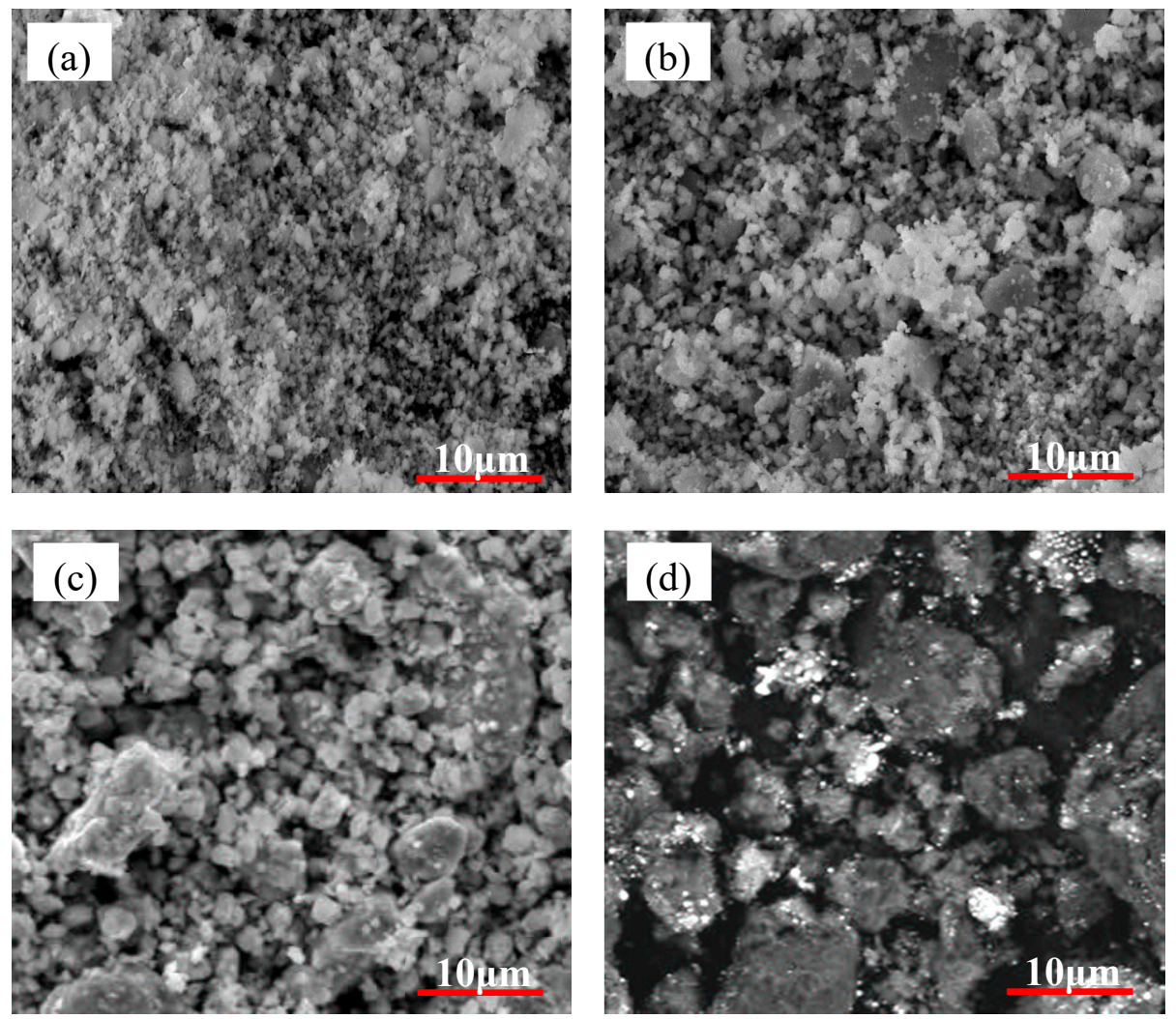

Figure 8. Abrasive dusts morphologies of $\mathrm{NiCr} / 10 \% \mathrm{hBN}$ composite at (a) $25^{\circ} \mathrm{C},(\mathbf{b}) 600{ }^{\circ} \mathrm{C},(\mathbf{c}) 700{ }^{\circ} \mathrm{C}$; and (d) $800{ }^{\circ} \mathrm{C}$. 


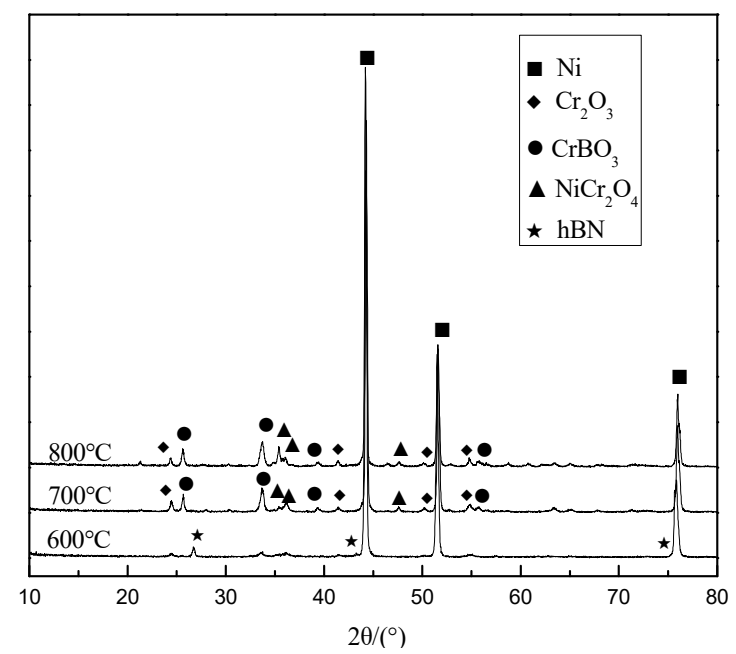

Figure 9. XRD patterns of abrasive at 600,700 , and $800{ }^{\circ} \mathrm{C}$.

At 700 and $800^{\circ} \mathrm{C}$, the strength of the $\mathrm{NiCr}$ alloy matrix significantly declines at high temperature, leading to phenomena such as increased plastic deformation of the material, enlarged frictional contact area, and crushing of the lubricating film. Thus, the tribological properties of $\mathrm{NiCr} / \mathrm{hBN}$ composite decline, as shown in Figures 5 and 6. At 700 and $800{ }^{\circ} \mathrm{C}$, increased hBN content gradually increases the friction coefficient and wear rate of $\mathrm{NiCr} / \mathrm{hBN}$ composite. At $700{ }^{\circ} \mathrm{C}$, abrasive dusts become granular and their particle sizes enlarge. At $800{ }^{\circ} \mathrm{C}$, these abrasive dusts are mainly large particles, as shown in Figure 8c,d. Figure 9 shows that at 700 and $800^{\circ} \mathrm{C}$, three spinel-type oxides $(\mathrm{Cr} 2 \mathrm{O} 3, \mathrm{CrBO}$, and $\mathrm{NiCr} 2 \mathrm{O} 4)$ appear as abrasive dusts in addition to $\mathrm{hBN}$ and $\mathrm{Ni}(\mathrm{Cr})$. This finding indicates that oxidation occurs on the wear surface and that oxides with high hardness are generated, so the sliding friction on the friction interface is aggravated. Hence, the friction coefficient of $\mathrm{NiCr} / \mathrm{hBN}$ composite is larger than that of the matrix metal at 700 and $800^{\circ} \mathrm{C}$, as shown in Figures 3 and 5. According to the analysis of wear-surface morphologies shown in Figure 7e,f, after oxides appear on the material surface at high temperature, the main wear mechanism of the composite transforms into scratching and gluing forms, which are the main wear forms of adhesive wear. During the wear process, shear failure occurs at the lubricating film layer with soft material texture and further develop toward the deep hard-metal layer accompanied by a large quantity of furrows, as shown in Figure 7e. This furrow effect continues to degrade the friction and wear properties of the composites. When plastic deformation at the contact peak point is large and the surface temperature is high, the stress of the adhesive bonding point enlarges. If the stress exceeds the shear strength of the composite itself, shear failure occurs at the deep metal part and gluing phenomenon occurs, as concretely manifested by the overall peeling off and large-scale peeling pits shown in Figure $7 f$.

\section{Conclusions}

(1) With increased friction temperature, the friction coefficient and wear rate of $\mathrm{NiCr} / \mathrm{hBN}$ self-lubricating composite gradually increase. i.e., friction and wear properties decline. However, friction and wear properties are favorable at $600{ }^{\circ} \mathrm{C}$, indicating that $\mathrm{NiCr} / \mathrm{hBN}$ self-lubricating composite has a wide operating temperature range of $25-600{ }^{\circ} \mathrm{C}$, which meets the working temperature requirement $\left(400-600^{\circ} \mathrm{C}\right)$ of the material.

(2) The main wear mechanism of $\mathrm{NiCr} / \mathrm{hBN}$ self-lubricating composite is abrasive wear at $<600{ }^{\circ} \mathrm{C}$. At $10 \% \mathrm{hBN}$ content, $\mathrm{NiCr} / \mathrm{hBN}$ composite has the optimum tribological properties.

(3) At 700 and $800{ }^{\circ} \mathrm{C}$, the friction and wear properties of $\mathrm{NiCr} / \mathrm{hBN}$ self-lubricating composite obviously decline, oxidation occurs on the wear surface, the spinel oxides $\mathrm{Cr} 2 \mathrm{O} 3, \mathrm{NiCr} 2 \mathrm{O} 4$, and $\mathrm{CrBO} 3$ are generated, the wear mechanism becomes combined scratching and gluing forms of adhesive wear, and the wear rate of the composite substantially increases. 
Author Contributions: X.Z. performed the property tests, analyzed the data, and wrote the paper. X.W. conceived/ designed the experiments. Y.H. provided guidance and assistance in the experiments. F.W. and P.Y. prepared the composites.

Funding: This research was funded by the Shaanxi Province Science and Technology Key Project (No. 2016NY-137) and the Fundamental Research Funds for the Central Universities (Nos. 2452017132 and 2452016075), respectively.

Conflicts of Interest: The authors declare no conflicts of interest.

\section{References}

1. Hong, K.H.; Kim, J.H.; Chang, K.; Kwon, J.Y. The role of Cr on oxide formation in Ni-Cr alloys: A theoretical study. Comput. Mater. Sci. 2018, 142, 185-191. [CrossRef]

2. Sushko, M.L.; Schreiber, D.K.; Rosso, K.M.; Bruemmer, S.M. Role of Cr-rich carbide precipitates in the intergranular oxidation of Ni-Cr alloys. Scr. Mater. 2018, 156, 51-54. [CrossRef]

3. Vialas, N.; Monceau, D. Effect of $\mathrm{Cr}$ content on interdiffusion and Kirkendall pore formation during homogenization of pack-aluminized $\mathrm{Ni}$ and $\mathrm{Ni}-\mathrm{Cr}$ wires. Intermetallics 2018, 101, 108-115.

4. Huang, X.Y.; Wang, J.H.; Zhang, H.Q.; Ren, J.; Zan, Q.F.; Gong, Q.M.; Wu, B. WC-Ni-Cr-based self-lubricating composites fabricated by pulsed electric current sintering with addition of WS2 solid lubricant. Int. J. Refract. Met. Hard Mater. 2017, 66, 158-162. [CrossRef]

5. Wang, Y.; Lei, K.; Ruan, Y.; Dong, W. Microstructure and wear resistance of c-BN/Ni-Cr-Ti composites prepared by spark plasma sintering. Int. J. Refract. Met. Hard Mater. 2016, 54, 98-103. [CrossRef]

6. Du, L.Z.; Zhang, W.G.; Liu, W.; Zhang, J.M. Preparation and characterization of plasma sprayed Ni3Al-hBN composite coating. Surf. Coat. Technol. 2010, 205, 2419-2424. [CrossRef]

7. Li, C.L.; Duan, L.C.; Tan, S.C.; Zhang, W.J.; Pan, B.S. Effect of CaF2 and hBN on the mechanical and tribological properties of Fe-based impregnated diamond bit matrix. Int. J. Refract. Met. Hard Mater. 2018, 75, 118-125. [CrossRef]

8. Chen, J.M.; Hou, G.L.; Chen, J.; An, Y.L.; Zhou, H.D.; Zhao, X.Q.; Yang, J. Composition versus friction and wear behavior of plasma sprayed WC-(W,Cr)2C-Ni/Ag/BaF2-CaF2 self-lubricating composite coatings for use up to $600^{\circ} \mathrm{C}$. Appl. Surf. Sci. 2012, 261, 584-592. [CrossRef]

9. Chen, W.E.I.; Zhang, D.; Lv, Z.L.; Li, H.Q. Self-lubricating mechanisms via the in situ formed tribo-film of sintered ceramics with hBN addition in a high humidity environment. Int. J. Refract. Met. Hard Mater. 2017, 66, 163-173. [CrossRef]

10. Tyagia, R.; Xiong, D.S.; Li, J.L.; Dai, J.H. Elevated temperature tribological behavior of Ni based composites containing nano-silver and hBN. Wear 2010, 269, 884-890. [CrossRef]

11. Pandaa, J.N.; Bijwea, J.; Pandeyb, R.K. Role of micro and nano-particles of hBN as a secondary solid lubricant for improving tribo-potential of PAEK composite. Tribol. Int. 2019, 130, 400-412. [CrossRef]

12. Wei, X.F.; Wang, R.C.; Peng, C.Q. Effect of BN surface plated nickel on sintering properties of Ni-Cr/BN antifriction sealing material. J. Cent. South Univ. 2010, 41, 150-155.

13. Jiang, B.Y.; Liu, S.M.; Wang, R.C. Effect of BN on mechanical and tribological properties of $\mathrm{BN} / \mathrm{Ni}(\mathrm{Cr})$ self-lubricating composites. Mater. Sci. Eng. Powder Metall. 2009, 14, 57-62.

14. Jiang, B.Y.; Wang, R.C.; Peng, C.Q. Influence of sintering temperature on structure and properties of BN/Ni(Cr) self-lubricating composites. J. Cent. South Univ. 2012, 43, 93-99.

15. Wang, C.C.; Wang, R.C.; Peng, C.Q. High temperature oxidation behaviours of Ni-20Cr/hBN self-lubricating composites. Chin. J. Nonferrous Met. 2013, 23, 356-361.

16. Ding, H.D.; Li, Y.W.; Hao, H.Q. Grey Equat ion between Bending Strength and Porosity of Copper Graphite Material. Chin. J. Nonferrous Met. 1996, 6, 123-126.

17. Blau, F.P.; Yust, C.S. Micro-friction studies of model self-lubricating surfaces. Surf. Technol. 1993, 62, 380-387. [CrossRef]

18. Xiong, D.S. Lubrication behavior of Ni-Cr-based alloys containing $\mathrm{MoS}_{2}$ at high temperature. Wear 2001, 251, 1094-1099. 